\title{
A Virtude Soberana e o Poder Judiciário no Brasil Contemporâneo ${ }^{1}$
}

\author{
The Sovereign Virtue And Judiciary In Contemporary Brazil
}

Igor Suzano Machado

Universidade Federal de Viçosa, Viçosa, MG, Brasil

Ludmila Mendonça Lopes Ribeiro

Universidade Federal de Minas Gerais, Belo Horizonte, MG, Brasil

Resumo: O presente artigo trata de três temas: em primeiro lugar, destaca-se, na trilha de Ronald Dworkin, que a igualdade é a virtude soberana da comunidade política e se o governo abre mão da igual consideração e respeito por todos os cidadãos, ele abre mão também de sua legitimidade, o que nos leva à importante questão de como tem sido construída a noção de igual consideração e respeito no Brasil; em segundo lugar, destaca-se que transformações políticas e sociais recentes levaram o Poder Judiciário a assumir uma posição cada vez mais proeminente na construção da verdade nas democracias ocidentais, refletindo sobre as consequências dessa mudança de paradigma; por fim, cruzando esses dois pontos, o artigo pretende refletir sobre a importância, as potencialidades e os limites, da função do Poder Judiciário de delimitar o conteúdo da virtude soberana da igualdade no Brasil contemporâneo.

Palavras-chave: Igualdade. Poder Judiciário. Brasil.
Abstract: This article deals with three themes. Firstly, it highlights, following Dworkin, that equality is the sovereign virtue of the political community and if the government neglects the equal concern and respect for all citizens, it also abandons its legitimacy, which leads us to the important question of how has been built up the notion of equal concern and respect in Brazil. Secondly, it highlights that recent political and social changes have led the judiciary to assume an increasingly prominent position in the construction of truth in Western democracies, reflecting on the consequences of this shift of paradigm. Finally, crossing these two points, the article reflects on the importance, potentials and limits of the role of the judiciary to define the contents of the sovereign virtue of equality in contemporary Brazil.

Keywords: Equality. Judiciary. Brazil.

1 Recebido em: 22/08/2013

Revisado em: 18/09/2013

Aprovado em: 03/02/2014 


\section{Introdução}

Nenhum governo é legítimo, diz Ronald Dworkin, a menos que demonstre igual consideração e respeito pelo destino de todos os cidadãos sobre os quais afirme seu domínio e aos quais reivindique fidelidade. A consideração igualitária, ele conclui, é a "virtude soberana" da comunidade política: sem ela o governo não passa de tirania (DWORKIN, 2005, p. IX-X). Tendo isso em vista, o presente artigo busca analisar como se relacionam no Brasil contemporâneo essa virtude política soberana e um de seus principais esteios de concretização: o Poder Judiciário. Como se relacionam, de um lado, o clamor pelo tratamento igualitário dos cidadãos brasileiros, como ditame de justiça e; do outro, operadores do Direito e instituições jurídicas como sujeitos e instâncias de construção de discursos que envolverão, necessariamente, considerações a respeito do que significaria exatamente essa exigência de igualdade.

Para cumprir seus objetivos, o trabalho tem seu desenvolvimento dividido em três partes, para além de sua introdução e considerações finais. Na primeira parte, a igualdade será apresentada como virtude política soberana e serão trazidos à tona seus contornos específicos no caso brasileiro. Isto é, a primeira parte tratará da relação entre a virtude soberana - igualdade - e o aqui - Brasil. Já a segunda parte, terá seu foco lançado sobre o Poder Judiciário e as mudanças que tal poder vem sofrendo nas últimas décadas, responsáveis por ampliar suas áreas de atuação e de influência. Ou seja, a segunda parte tratará da relação entre o Poder Judiciário e o agora. Por fim, a terceira parte fará a ponte entre as duas primeiras, destacando qual seria a importância do Poder Judiciário contemporâneo para a formatação da igualdade no Brasil, focalizando a virtude soberana, aqui e agora.

Muitos cientistas sociais brasileiros, na esteira de Roberto DaMatta (1984), põem em destaque o tratamento quase esquizofrênico dado ao princípio da igual consideração e respeito por instituições jurídicas, políticas e culturais no Brasil. Esse princípio alterna posições entre o centro do ordenamento jurídico advindo da Constituição de 1988 e o vocábulo vazio que indica um princípio sem correspondência fática. Seu destino está guardado na construção de discursos de efetivação ou de diminuição 
da igualdade que vierem a emergir numa parte da história do país que ainda está para ser escrita. E um capítulo importante dessa história será escrito nas instâncias judiciais brasileiras, que têm ganhado destaque como centros de produção de verdades. Logo, resta fundamental analisar como tem se dado e como precisa se dar a relação entre nossa justiça, como instituição, e nossa justiça como valor, tributária, necessariamente, da virtude soberana da igualdade. Esse é o objetivo do presente estudo.

\section{A Virtude Soberana e o Aqui}

A igualdade é a viga mestra da justiça. Não é à toa que Ronald Dworkin a considera a "virtude soberana" da comunidade política. Isso mesmo sendo um autor assumidamente liberal, pertencendo, portanto, a uma tradição intelectual que tem benquista outra virtude que poderia se contrapor à igualdade e sobre ela prevalecer: a liberdade. Mas Dworkin não está sozinho quando afirma que o âmago de uma justiça liberal não reside na liberdade e sim na igualdade: desde a Teoria de Justiça como Equidade de John Rawls (RAWLS, 2002), o assim chamado liberalismo igualitário tem se destacado como uma das principais correntes teóricas dentro dos debates contemporâneos sobre a questão da justiça.

A importância da igualdade na política, como virtude responsável pela construção de uma ordem social justa, pode ser ilustrada pela lição de Amartya Sen, que muito bem explicita o ponto, quando afirma que as principais teorias éticas do ordenamento social compartilham todas elas uma aprovação da igualdade sobre alguma variável (como igualdade perante a lei, igualdade de recursos, igualdade material, igualdade de renda, etc.), mesmo que haja divergências a respeito de qual variável deve ser focalizada. Segundo ele, existe uma razão para esse "igualitarismo" aparentemente onipresente: a plausibilidade ética dificilmente é obtida a menos que se dê, a toda pessoa, igual consideração em algum espaço importante numa teoria particular, isto é, que se estenda a igual consideração a todos em algum nível. (SEN, 2001, p. 31-33)

Isso porque o raciocínio ético para um ordenamento social precisa ser acreditável sob o ponto de vista dos outros, potencialmente todos 
os outros. Ou seja, a pergunta "por que esse sistema?" precisaria ser respondida como se fosse para todos os participantes desse sistema (SEN, 2001, p. 48-49). Logo, uma ordem social justa deve ser em alguma medida igualitária e quando se fala em justiça se está, de certa maneira, fazendo referência à igualdade que é assim, como bem destaca Dworkin, nossa virtude soberana. Por conseguinte, indignar-se com a injustiça é, num mesmo sentido, indignar-se com a desigualdade em determinada dimensão. Portanto, se se condena um Brasil injusto, está sendo condenado um Brasil que é, em alguma medida, desigual. Ao mesmo tempo, quando se clama por justiça no país, o que se faz é clamar por algum sentido de maior igualdade.

Mesmo assim, conforme ficou claro no ensinamento de Amartya Sen, a simples exigência da igualdade não nos diz muito, restando necessário responder a outra pergunta fundamental: quando se fala em igualdade, refere-se à igualdade de quê? Nesses termos, por exemplo, Dworkin tece a seguinte reflexão: se a igual consideração é pré-requisito da legitimidade política, não se pode deixar de lado a questão relativa àquilo que a igual consideração requer. Seria suficiente a comunidade garantir um nível mínimo de nutrição, alojamento e cuidados médicos para todos e, então, não se interessar por saber se alguns cidadãos possuem muito mais riquezas do que outros? É preciso perguntar: essa política atenderia à demanda por igual consideração para aqueles que continuam sem poder nem mesmo sonhar com a vida que alguns de seus concidadãos têm como certa? (DWORKIN, 2005, p. XI)

Esse é um tipo de questionamento que, ao lado de outros como, por exemplo, referentes à importância do mérito na distribuição das riquezas, permite ressonância aos dizeres de Ruy Barbosa quando ele proclama que "igualdade é aquinhoar desigualmente os desiguais na medida de sua desigualdade". Contudo, mais do que garantir a meritocracia ou mitigar desigualdades materiais mais profundas, o ensinamento de Ruy Barbosa tem servido no Brasil à mera propagação da desigualdade em função de características pessoais. Como destaca Regina Lúcia Teixeira Mendes da Fonseca, a máxima de Ruy Barbosa, quando assimilada nesses termos, sintetiza a regra jurídica da igualdade tal como ela é concebida no Brasil até hoje, ao pressupor tratamento jurídico desigual para pessoas so- 
cialmente desiguais. O que acontece, no entanto, é que essa forma de apropriação do princípio da igualdade, ao afastar a ideia de um mínimo comum, dificulta a identificação da cidadania brasileira e derruba toda a inspiração liberal do autor da máxima. Afinal, o liberalismo concebe uma sociedade formada por indivíduos aos quais pode ser atribuído um mínimo comum de direitos que tem por objetivo reduzir a desigualdade de fato, própria da economia de mercado. (FONSECA, 2005, p. 21)

Isso faz com que a igualdade - que já é por si só um princípio demasiadamente complexo, capaz de evocar significações múltiplas e por vezes conflituosas - no Brasil ganhe contornos ainda mais complicados, trazidos constantemente à reflexão pelas ciências sociais locais. Por exemplo, Roberto DaMatta destaca que no país existiriam duas ordens em conflito que tocam diretamente a questão da igualdade: uma ordem formal na qual prevaleceria a noção de indivíduos, todos iguais uns aos outros, e uma ordem informal na qual prevaleceria sobre a noção de indivíduo a noção de pessoa, de modo que as relações pessoais de cada um o colocariam em situação de desigualdade perante outros brasileiros que não gozassem das mesmas relações. A ordem formal, segundo o autor, encontraria respaldo na legislação nacional que se submete ao princípio da igual consideração jurídica do Estado por todos. Já a ordem informal encontraria reflexo em manifestações culturais corriqueiras no dia-a-dia, ganhando forma em institutos como o "jeitinho brasileiro" e a famigerada expressão "você sabe com quem está falando?" Nas palavras do próprio Roberto DaMatta:

O dilema brasileiro residia numa trágica oscilação entre um esqueleto nacional feito de leis universais cujo sujeito era o indivíduo e situações onde cada qual se salvava e se despachava como podia, utilizando para isso o seu sistema de relações pessoais. Haveria assim, nessa colocação, um verdadeiro combate entre leis que devem valer para todos e relações que evidentemente só podem funcionar para quem as tem. O resultado é um sistema social dividido e até mesmo equilibrado entre duas unidades sociais básicas: o indivíduo (o sujeito das leis universais que modernizam a sociedade) e a pessoa (o sujeito das relações sociais, que conduz ao pólo tradicional do sistema). Entre os dois, o coração do brasileiro balança. E 
no meio dos dois, a malandragem, o "jeitinho" e o antipático "sabe com quem está falando?" seriam modos de enfrentar essas contradições e paradoxos tipicamente brasileiros. Ou seja: fazendo uma mediação também pessoal entre a lei, a situação onde ela deveria aplicar-se e as pessoas nela implicadas, de tal sorte que nada se modifique, apenas ficando a lei um pouco desmoralizada - mas, como ela é insensível e não é gente como nós, todo mundo fica, como se diz, numa boa, e a vida retorna a seu normal [...] (DAMATTA, 1984, p. 95-97)

No entanto, a ordem tida por Roberto DaMatta como formal, também abriga elementos da cultura, que ele considera informal, segundo a qual a relação entre os brasileiros não estaria pautada por normas gerais e princípios meritocráticos relativos ao indivíduo, mas sim por características relativas à pessoa. Como exemplo disso, pode-se destacar determinadas normas do Código de Processo Penal relativas, por exemplo, ao foro privilegiado e à prisão especial. Na verdade, essas duas ordens de consideração dos cidadãos brasileiros encontram reflexos tanto em manifestações diárias informais, quanto na formalidade da legislação e das decisões do Poder Judiciário. Inclusive, elas sobrevivem em cada uma das dimensões formal e informal, devido a sua alimentação em uma, pela outra.

Como operadores dessa via de mão dupla, estão aqueles responsáveis pela produção de discursos formadores de verdades. E se, como destacam Antoine Garapon e Ioannis Papadopoulos, uma cultura jurídica constitui um modo específico de produção da verdade (2008, p. 12), dentre esses operadores, é possível destacar os chamados operadores do Direito - juízes, advogados, promotores, etc. - responsáveis pela criação dos discursos formadores das verdades jurídicas, definidoras do que pertenceria aos campos do lícito e do ilícito, uma das dimensões do certo e errado de uma sociedade. E dentre esses operadores, têm destaque especial os juízes, que, como bem destaca Regina Lúcia Teixeira Mendes da Fonseca, ocupam posição hierárquica privilegiada dentro da produção da verdade no campo jurídico brasileiro, acima de advogados e mesmo doutrinadores. 
Seguindo a autora, pode-se dizer que o sistema jurídico brasileiro é um campo semiautônomo integrado por iniciados em um saber com características específicas, organizados dentro desse campo de forma hierárquica. No topo dessa hierarquia estão os juízes que detêm o poder de interpretar e decidir sobre o direito posto, seguidos pelos doutrinadores, que detêm prestígio singular por serem intérpretes, autorizados pelo campo, das leis e das práticas judiciais. Contudo, esses doutrinadores exercem função mais formadora e reprodutora do saber jurídico, o que, sem dúvida, lhes concede algum poder, mas nada que se equipare ao dos julgadores. (FONSECA, 2008, p. 14)

Por conseguinte, os juízes passam a encarnar posição privilegiada na definição do que é a igualdade no Brasil, quando ela invade as questões jurídicas - o que, dada a centralidade do princípio na nossa nova ordem constitucional, é corriqueiro. É a eles que caberá, quando da interpretação que perpassa necessariamente a atividade jurisdicional, fazer a escolha entre uma orientação universalista ou particularista, responsáveis por formar os dois eixos classificatórios da justiça brasileira, naquilo que Roberto Kant de Lima (apud OLIVEIRA, 2002, p. 13) chama de "o paradoxo legal brasileiro" que equaciona, de um lado, princípios constitucionais liberais igualitários e, de outro, um sistema judicial hierárquico associado, por exemplo, a práticas policiais discricionárias. E isso, principalmente, quando se leva em conta as transformações contemporâneas por que tem passado o Poder Judiciário, que, conforme se verá adiante, expandem o escopo e o impacto de suas decisões.

\section{O Poder Judiciário e o Agora}

O Poder Judiciário atravessou transformações importantes durante as últimas décadas. Os juízes passaram a ter mais poder e a influenciar mais dimensões da vida social e política, permitindo que alguns autores aludam ao fenômeno da "judicialização da política e das relações sociais" (WERNECK et al., 1999). Dentre os fatores que permitiram e impulsionaram essa judicialização nas últimas décadas, é possível destacar a influência do sistema político e judicial norte-americano, com a vitória dos 
Estados Unidos na Segunda Guerra Mundial; a queda, com o fim dessa guerra, de regimes totalitários derivados do princípio majoritário; e o reavivamento de teorias de justiça reformuladas por filósofos políticos e do Direito.

Esmiuçando os três pontos, pode-se dizer que, nos Estados Unidos, a separação dos poderes, voltada para um sistema de pesos e contrapesos, já conhecia o poder de revisão das decisões legislativas pelo Poder Judiciário - e, por conseguinte, a influência do Judiciário na política - e o aumento da influência global desse país têm como reflexo o aumento de influência de seu sistema político. Igualmente, a conquista do poder por regimes totalitários, mesmo em sistemas democráticos sujeitos à regra da maioria, revelou que algo além dessa regra deveria ser exigido para garantir a própria sobrevivência da democracia, sendo necessária, por consequência, uma maior atuação do Poder Judiciário como protetor qualificado desse "algo além" que se refletiria em direitos individuais, princípios democráticos e cláusulas constitucionais pétreas. Por fim, não obstante o enfraquecimento das teorias jusnaturalista, em face de teorias juspositivistas e de teorias deontológicas da justiça, como a de John Rawls e Ronald Dworkin, voltaram à discussão acadêmica propondo um direito, para além das formalidades, garantidor de justiça e bem-estar, ressaltando mais uma vez, a importância, nesse contexto, da atuação do Poder Judiciário.

Como consequência, os autores que têm se debruçado sobre a análise do fenômeno da judicialização têm destacado a contínua expansão do poder e da responsabilidade dos juízes no sistema democrático, ocupando funções que até então cabiam exclusivamente a outros poderes da República ou encontravam solução em arenas outras que não propriamente a judiciária. Isso porque esse novo contexto derrui a autonomia do Direito como mera aplicação sistemática de normas criadas em outros centros de poder, concentrando de forma inédita a produção da verdade jurídica nas mãos dos juízes e não na dos legisladores. Como destaca Garapon (2001, p. 40-41), pode-se dizer que, atualmente, a lei não é mais suficiente para guiar o juiz em suas decisões, devendo ele apelar para fontes externas antes de proferir sua sentença. A lei não se confunde mais com o direito: guarda com ele íntima relação, mas não é mais capaz de fundamentar, 
sozinha, todo o sistema jurídico. Hoje em dia, é necessário conceber o direito como um conjunto não só de regras, mas também de princípios, e tomar a lei como um produto semiacabado que deve ser terminado pelo juiz.

Conforme destaca Cappelletti (1993, p. 26-27), como atividade interpretativa, a aplicação das leis pelo Poder Judiciário sempre envolveu certa dose de criatividade, reservando sempre aos juízes alguma autonomia e responsabilidade por suas decisões. No entanto, com as transformações citadas anteriormente, essa margem de criatividade da decisão judicial foi ampliada e se tornou cada vez menos negligenciável, tanto pelo próprio prolator da decisão quanto por seus analistas. O chamado ativismo judicial seria assim, um aumento da necessidade e da intensidade de uma criatividade judiciária que sempre existiu. Dessa forma, o ponto-chave seria destacar quais seriam os motivos desse aumento de necessidade e de intensidade, como causas desse "ativismo", que assim, estaria mais relacionado à radicalização de uma função já existente do que à assimilação de função nova.

Tendo isso em vista, para além dos fatores já citados, Cappelletti (1993) destaca que os juízes foram de certa forma "empurrados" em direção ao "ativismo" - isto é, empurrados em direção a uma atividade interpretativa mais cobrada e num maior nível de intensidade - por fatores como a crítica ao formalismo, a legislação social do welfare state, o declínio da confiança no Poder Legislativo, a massificação oriunda da revolução industrial (e consequente proteção de direitos difusos e coletivos) e a inserção de cartas de direitos humanos nos modernos ordenamentos jurídicos.

A crítica ao formalismo ressaltou o papel da escolha - então encoberto pela visão do processo judicial como simples fórmula - expondo a responsabilidade dos juízes por suas decisões, que não seriam assim, resultado de um mero procedimento. Da mesma forma, com a legislação social do welfare state, o Estado assumiu papéis além da repressão e da proteção, responsabilizando-se por direitos sociais que exigem sua intervenção ativa ao longo do tempo. A formulação legislativa passaria, dessa maneira, a contar com termos mais vagos, imprecisos e voltados para o 
futuro, e não passado, exigindo sua concretude através da atividade criativa e de interferência política por parte dos juizes.

Além disso, os parlamentos, fonte tradicional do direito, tiveram sua legitimidade atacada com base na sua formação por políticos profissionais, voltados para a reeleição e perpetuação no poder, com interesses de curto prazo, comprometidos com prioridades locais, corporativas ou de grupo, o que exigiria a ação do Poder Judiciário como contraponto necessário ao Legislativo, num sistema de checks and balances. E isso é igualmente válido com relação ao Poder Executivo, que se "agiganta" com o Estado de bem-estar social e exige o mesmo "gigantismo" do Judiciário para manter o equilíbrio de forças entre os três poderes.

Por fim, a sociedade de massas oriunda da revolução industrial trouxe à tona os direitos difusos e coletivos que requerem para sua proteção e efetivação a atuação dos juízes além do processo tradicional que envolve atores individuais. Já que os interesses de grupos passam a dar o tom das relações sociais atuais, deveria o Judiciário, para além dos outros poderes já acostumados com a representação coletiva, desenvolver meios de concretizá-los além dos, ou até mesmo, em detrimento dos, demais poderes. E o mesmo pode ser dito a respeito dos direitos e das garantias fundamentais inscritas nas modernas ordens constitucionais por meio das chamadas "cartas de direitos", que devem ser protegidas de uma possível "orgia de leis" no parlamento, ou de um possível autoritarismo na administração. Sua proteção faz necessária a atuação criativa do Poder Judiciário, tendo em vista que, inclusive, tais direitos envolvem valores e preceitos vagos e conflituosos que exigem a interpretação judicial como forma necessária de concretização.

Por conta disso, contemporaneamente, o juiz irrompe como ator social dotado de uma responsabilidade inédita na produção da verdade. No caso brasileiro, esse quadro se intensifica com a promulgação da Constituição de 1988 e as profundas transformações a que submeteu o Poder Judiciário e o Ministério Público do país. Com a nova carta constitucional, o Poder Judiciário brasileiro teve seu papel republicano redefinido. Na transição para a democracia, sob uma circunstância mundialmente generalizada de reestruturação da relação entre o Estado e a sociedade, em 
consequência das grandes transformações produzidas por mais um surto de modernização do capitalismo, tal poder foi alçado ao primeiro plano da vida pública ao ser demandado por nova clientela a atuar como esfera de ampliação de direitos (VIANNA et al. 1997, p. 11-12). Chamado a dirimir os impasses institucionais entre o Executivo e o Legislativo e a garantir direitos de cidadãos e empresas em face do intervencionismo estatal, além de exercer novo papel de garantir a integridade do tecido social em pontos-chave, como a desintegração familiar, por meio do direito de família e do menor, o Judiciário se vê inserido num forte contexto de ampliação de sua esfera de atuação, permitindo que se fale, nesse contexto, da judicialização da política e das relações sociais também no Brasil.

Em qualquer sociedade, vários são os campos de produção de verdades, cada um com suas características e responsabilidades específicas. De acordo com o campo em questão e a sociedade em que esse campo está situado, várias são as possibilidades de abordagem e de peso possuído por cada instância dentro do campo e de cada campo dentro do conjunto social. Há contextos em que a igreja ocupa, nesse sentido, posição central, e outros, por exemplo, em que têm destaque a mídia ou a academia. Em cada um desses campos, a forma de produção da verdade encontra peculiaridades, contando, dentre outros, com um tempo próprio e com porta-vozes que baseiam a legitimidade de seus dizeres em fontes diversas.

Dizer que o Poder Judiciário contemporâneo amplia sua importância como fonte de produção da verdade, como acontece no caso brasileiro, não implica dizer que ele passa a ser a única ou a principal dentre essas fontes, mas apenas que ganha, nessa função, força que não possuía outrora. Mesmo assim, já que as verdades que produz são capazes de se apoiar no aparelho repressivo estatal, sua importância é grande. E as consequências trazidas à tona por essa mudança são importantes. Por exemplo, sabe-se que o Judiciário trabalha num tempo diferente do da mídia, que contrapõe, ao imediatismo desta, um tempo expandido, baseado em interesses outros. Assim sendo, pode-se assistir a um fortalecimento do Judiciário numa comunidade em que a mídia se destaca como fonte de produção da verdade. Isso pode trazer como consequência cenários em que a relação entre essas esferas seja de aberta concorrência, de certa coo- 
peração, ou de total submissão de uma à outra, dependendo do momento e do assunto em que a disputa pela produção da verdade se dá.

Além disso, tem-se que o Direito é um saber local (GEERTZ, 2008), e a ampliação da participação de instituições do Direito na produção da verdade implica o destaque da cultura e da sensibilidade jurídicas locais, que passam a desempenhar papel importante na definição de suas palavras autorizadas. Isso quer dizer que, tomando como análise a produção da verdade no sistema judiciário brasileiro, é preciso levar em conta que para além dessa produção se fortalecer no contexto contemporâneo - podendo desenvolver relações das mais diversas com outras esferas de produção autorizada da verdade - ela também explicita, nessa função, os traços que singularizam a cultura e sensibilidade jurídicas do país.

Cada uma das duas grandes tradições jurídicas do Ocidente, a tradição jurídica da Civil Law e a Tradição jurídica da Common Law, tende a conformar culturas jurídicas específicas de características semelhantes, por mais que uma série de minúcias faça com que ela nunca seja exatamente a mesma em dois países de uma mesma tradição. Dentro dessa conformação, tem-se que as culturas jurídicas que abraçam a tradição da Civil Law reconhecem a primazia da política sobre o Direito e uma forma de produção da verdade que busca desvendar uma verdade unitária, tendo por consequência a centralização e a verticalização da produção do Direito. Por outro lado, as culturas jurídicas vinculadas à tradição da Common Law reconhecem a anterioridade do Direito perante a política e uma forma de produção da verdade que se baseia na confrontação de relatos concorrentes, tendo por consequência uma produção do Direito mais horizontal e descentralizada. Já quanto às sensibilidades jurídicas específicas que tendem a gerar essas tradições, tem-se que, no ambiente da Civil Law, costuma prevalecer a desconfiança sobre os indivíduos, a aposta em um processo de partes mais passivas e o enfoque em direitos substantivos, enquanto, no ambiente da Common Law, tende a prevalecer a confiança nos atores e, consequentemente, em partes mais ativas durante o processo, assim como o enfoque nas normas processuais, isto é, nas "regras do jogo". 
O Direito brasileiro é histórica e sociologicamente vinculado à tradição jurídica da Civil Law, característica dos países da Europa Continental e América Latina, e não à tradição da Common Law, característica do Reino Unido e suas colônias, dotada de especial desenvolvimento nos Estados Unidos. Nesse contexto, floresceu no país uma cultura jurídica centrada nas leis dos códigos em detrimento dos princípios constitucionais, conforme manda uma tradição jurídica em que a política e, consequentemente, as manifestações do Poder Legislativo, deve ter prioridade perante direitos individuais pretéritos. Para além da primazia da política, encontrou amplo respaldo na cultura jurídica brasileira a primazia do público e do Estado, como seu representante privilegiado, perante os cidadãos. Como consequência, tem destaque, no processo judicial pátrio, a figura do juiz, muito mais do que das partes, sendo o objetivo desse processo mesmo, muito menos a confrontação de versões concorrentes sobre o fato do que a descoberta de uma verdade única a ser desvendada pelo Poder Público.

Tendo em vista essas observações, quais são as consequências da nova configuração do Poder Judiciário para a formulação de discursos sobre a verdade a respeito da igualdade no Brasil? Como tem atuado e como deveria atuar o Poder Judiciário nacional quando chamado, como tantas vezes é, a dar sua opinião sobre o que exatamente significaria tratar os cidadãos brasileiros com igual consideração e respeito? É esse ponto de intersecção entre a emergência de um novo Judiciário na realidade brasileira contemporânea e um princípio de justiça que é a virtude soberana da comunidade política e sobre o qual os juízes são instados a se manifestar, o tema a ser tratado a seguir.

\section{O Poder Judiciário e a Virtude Soberana, Aqui e Agora}

Conforme foi visto, a dimensão central da justiça, a igualdade, possui contornos muito específicos dentro do caso brasileiro. Se por um lado, esse princípio encontra respaldo numa ordem constitucional igualitária, baseada na noção de indivíduos iguais perante a lei, por outro, perduram institutos diferenciadores desses indivíduos que não se baseiam no méri- 
to, mas sim em características como relações pessoais, posses e tipo de ocupação. Isso não é observável apenas em institutos como o "jeitinho brasileiro" e o "você sabe com quem está falando?", mas na própria ordem jurídica, que deveria estar submetida ao princípio de igual consideração por todos, porém dispõe de institutos diferenciadores como a prisão especial para preso que tem como característica diferenciadora sua apenas ter concluído um curso superior.

Não é o caso de duas óticas que informam uma a dimensão legal formal e outra a dimensão cultural informal. Tampouco se trata de um caso em que "na prática a teoria é outra", pois, como bem salienta Regina Lúcia Teixeira Mendes da Fonseca (2005, p. 2), o que se observa é a coexistência de duas teorias que informam a prática e o discurso. Como destaca Roberto Kant de Lima (apud FONSECA, 2005, p. 25-27), o caso brasileiro não se caracterizaria por um lado, pela simples ausência de um modelo de sociedade do tipo "paralelepípedo", em que todos partem da base para topo em situação de igualdade para atingi-lo, e, por outro, pela presença do modelo de sociedade do tipo "pirâmide", em que apenas uma parte daqueles que partem da base podem realmente chegar ao topo. $\mathrm{O}$ caso brasileiro seria, na verdade, o de uma sociedade que sobrepõe o paralelepípedo e a pirâmide, inclusive, em suas instituições jurídicas, gerando um discurso sobre a igualdade quase esquizofrênico. Dada sua incompatibilidade, em cada caso, faz-se necessário se decidir a favor de um deles, no sentido mais estrito de uma genuína opção política ou moral.

Com a promulgação da Constituição de 1988, num contexto internacional de judicialização da política e das relações sociais, o Poder Judiciário - tornando-se mais independente e invadindo cada vez mais esferas - consolidou-se como uma das principais instâncias de produção da verdade na realidade brasileira. Seu pronunciamento sobre a legalidade, ou ilegalidade, de atos do governo ou de particulares, sua imposição de culpabilidade penal e seu gerenciamento da constitucionalidade das leis são a palavra final sobre tais assuntos, por mais que se construam entendimentos divergentes na academia, na imprensa e nos parlamentos. E, dentro de todo o campo jurídico como instância de produção da verdade, ganha cada vez maior destaque a posição do juiz, que, como foi visto, ocupa o vértice da organização hierárquica do campo. 
Todavia, a reboque do poder dos juízes, cresce também o poder dos membros do Ministério Público, dos advogados e defensores públicos e da polícia, importantes elos na cadeia de produção da verdade judiciária, ao ocuparem posição de destaque na informação dos juízes. Mesmo que nas disputas pela verdade dentro do campo, prevaleçam as decisões finais, sempre obra de juízes, os casos de cooperação não podem ser negligenciados, pois o atributo da inércia faz com que parte considerável da decisão do juiz se baseie no que lhe foi apresentado por esses outros agentes, além do que lhe foi transmitido, ao longo de sua formação, pela já citada doutrina jurídica. Na esfera penal, por exemplo, não há como negar a importância que possui, para a informação do juiz, o inquérito policial (FONSECA, 2008), o que faz com que o aumento do poder dos juízes na produção da verdade acarrete também um aumento do poder da polícia.

Igualmente, da mesma forma que a produção da verdade no Judiciário pode apresentar um contraponto interessante à verdade midiática, há que se destacar também os possíveis riscos que podem existir na cooperação entre essas duas instâncias. Se, por um lado, o ritual judiciário e o ritmo diferenciado do seu tempo podem evitar que a verdade sobre determinado fato seja inteiramente obra de uma imprensa mais preocupada com a manchete chamativa e com o retorno do público alvo de seus patrocinadores, por outro, a instrumentalização da mídia por membros da "cena judiciária" pode macular irremediavelmente essa cena. Trata-se de um risco posto em destaque por Garapon e que, no caso brasileiro, tem destaque na "seletividade" da escolha de casos a serem investigados pelo Ministério Público, como põe em destaque Gláucia Maria Pontes Mouzinho (2007).

Cruzando essas conclusões, tem-se que o Poder Judiciário, em especial, os próprios juízes, mas também os demais órgãos e funções da justiça, ou outros campos que venham a colaborar com ela, ocupam um lugar privilegiado na construção da verdade sobre determinados assuntos no Brasil. Um desses assuntos, inevitavelmente, será o significado de tratar com igual consideração e respeito os cidadãos brasileiros, já que a igualdade foi potencialmente juridicizada ao ser assimilada como princípio fulcral da ordem jurídica e política almejada pela nova Constituição. 
Logo, torna-se inescapável aos operadores da justiça brasileira ocupar lugar de destaque e assumir grande responsabilidade nas decisões políticas e morais aludidas anteriormente: nas decisões de optar entre a lógica universalista e a lógica particularista na sua função de interpretar a lei, que daria guarida tanto a uma quanto à outra, no que tange à significação do que seria a igual consideração e respeito por todos.

Nesse ponto, certamente terão destaque traços da cultura e da sensibilidade jurídicas locais. Por exemplo, num confronto entre a norma específica que prevê a prisão especial para portadores de diploma de conclusão de curso superior e o princípio geral da isonomia, a argumentação legalista de que deve prevalecer o disposto em lei sobre o caso específico, e não um princípio constitucional abstrato, pode se combinar de forma perigosa com uma cultura judiciária inquisitorial em que não são julgados os fatos, mas sim as pessoas, valorizando, mais uma vez, particularidades pessoais mais do que o tratamento isonômico abstrato.

É possível que esse exemplo caduque em breve, dada a expectativa de que uma reforma iminente do Código de Processo Penal reformule o instituto da prisão especial, fazendo com que mesmo uma interpretação focada nos códigos, nos moldes da tradição da Civil Law, não permita a diferenciação dos presos com base no seu grau de instrução. Mesmo assim, ainda restariam casos insolúveis pela mera reforma legal. Por exemplo, nos casos julgados durante a transição de uma norma para a outra, a reforma seria considerada meramente processual, ou mista? Seria reconhecida a possibilidade de a nova regra abranger casos já em andamento, ou se interpretaria que a desqualificação desse critério diferenciador baseado no grau de instrução implicaria mitigação de direito material do réu?

Isso sem contar que, como foi dito, o aumento do poder dos juizes traz a reboque o aumento do poder de outras instâncias em colaboração com a justiça, como a polícia. Que tipos de mudança seriam necessárias, por exemplo, para fomentar mudanças nas atitudes policiais? Esse seria um dos pontos que incidiria pungentemente na possibilidade de a lei modificar práticas sociais profundamente enraizadas no país, conforme demonstra a descrição seguinte de José Murilo de Carvalho, referindo-se a uma experiência pessoal, na qual foi chamado a socorrer uma senhora 
traumatizada com a invasão de sua casa pela polícia. Relatando sua indignação sobre o fato ao agente da lei, deparou-se ele com a seguinte situação:

Expliquei o caso, argumentei que poderiam ter causado a morte da pobre velha. O sargento não se abalou. Admitiu terem sido ele e um colega os autores do feito, mas negou a acusação: "Não invadi, doutor, não arrombei; foi apenas o peso do meu corpo que forçou a porta do casebre". Continuou explicando que a mulher se declarara crente e fora bem tratada. Havia uma acusação de roubo de galinha - o clássico roubo de galinha! - contra os filhos da mulher, dai a razão da investigação policial. Completou afirmando que o local era ponto de macumba e talvez de tráfico de drogas, o que justificava plenamente a ação da polícia.

E dessa situação concluiu:

Esta é a pequena história. Que exegese podemos fazer? O que ela nos revela sobre a cidadania em nosso país?

De início, podemos verificar que, naquele contexto, a igualdade de todos perante a lei, estabelecida no artigo $5^{\circ}$ da Constituição em vigor, é balela. Quem define a cidadania, na prática, é a polícia. $\mathrm{Na}$ curta conversa de dez minutos com um agente da lei, com alguém que deveria implementar os dispositivos constitucionais, descobrimos que ele estabelece, por conta própria, três classes de cidadãos, a saber: o doutor, o crente, o macumbeiro. Doutor é o cidadão de primeira classe, titular dos direitos constitucionais, merecedor do respeito e da deferência dos agentes da lei. O crente vem em segundo lugar: pode ter alguns direitos violados, mas ainda merece algum respeito. Por fim, o macumbeiro: não tem direitos, nem pode ser considerado cidadão. (CARVALHO, 1992, p. 87-125)

Ainda assim, deve-se ter em mente que, como destacam Antoine Garapon e Ioannis Papadopoulos, uma cultura jurídica

[...] não dita nada, não constrange a vontade política, não paralisa os determinismos sociológicos, jamais imuniza completamente 
contra as derivas mais graves, mas, sim, favorece ou impede, as prepara ou retarda. (GARAPON; PAPADOPOULOS, 2008, p. 9)

É especialmente importante que esse ponto seja percebido num contexto mundial de reconfiguração do Poder Judiciário, numa direção, em termos sociológicos, a uma maior responsividade social (NONET; SELZNICK, 2010), ou, em termos teórico-jurídicos, a um paradigma pós-positivista (BARROSO, 2009). Nesse contexto, uma aproximação cada vez mais intensa entre as duas grandes tradições jurídicas ocidentais tem gerado uma série de tensões e transformações que não podem ser negligenciadas.

Inserida nessa paisagem, é interessante notar como tem se transformado e reagido a essas transformações a cultura jurídica brasileira. Um aspecto fundamental dessa mutação, conforme destacam Luiz Werneck Vianna e José Eisenberg (NONET; SELZNICK, 2010, p. 7-8) diz respeito à mudança do centro gravitacional do nosso ordenamento jurídico do Código Civil para a Constituição Federal. Com isso, novas interpretações pós-positivistas do Direito, mais atentas a princípios e menos obcecadas por regras, têm florescido no campo jurídico do país, relembrando aos seus operadores que seu campo é um campo de produção da verdade em que princípios, como a igualdade, podem e devem ser discutidos e reinterpretados.

Ou seja: o momento é de transição e o debate encontra-se em aberto. Voltando a Ronald Dworkin, que nos forneceu o tratamento da igualdade enquanto nossa virtude soberana, é possível tomar desse autor também sua caracterização alegórica da atividade judiciária enquanto um "romance em cadeia”. Isto é, cada agente engajado nas práticas judiciárias, seja o legislador responsável pela produção do texto legal, seja o doutrinador responsável por lhe fornecer interpretação mais coerente, seja o juiz que irá decidir o caso, é responsável por escrever um capítulo desse romance, tentando formar um todo coerente, apesar das diferenças de tempo e espaço em que estão inseridos. E essa coerência para Dworkin, deve ser buscada enquanto uma coerência de princípios, em que ocupa posição central o metaprincípio da igual consideração e respeito por todos os cidadãos, base da legitimidade do Estado (DWORKIN, 2003). Portanto, fazendo 
uso da alegoria de Dworkin, pode-se dizer que, no que tange ao princípio da igualdade no Brasil, seu significado em muito depende do que for escrito nos próximos capítulos do romance em cadeia do nosso Direito.

\section{Conclusão}

As reflexões anteriores mostraram as potencialidades e os riscos contidos na assunção, por parte de um Poder Judiciário cada vez mais influente, da função de construir um discurso sobre o que significaria tratar os cidadãos brasileiros com igual consideração e respeito. Nesse contexto, foi questionada a assimilação da máxima de inspiração aristotélica de Ruy Barbosa de que a igualdade é aquinhoar de forma desigual os desiguais na medida de sua desigualdade. O perigo residente nessa máxima é o de se perpetuar no campo jurídico tratamentos desiguais que se baseiam em critérios que não se relacionam com o mérito ou com qualquer política compensatória, mas no escalonamento dos cidadãos de acordo com suas ocupações, nível de instrução, relações pessoais, etc.

Isso não que dizer que a máxima de Ruy Barbosa deve ser abandonada. Apenas que ela deve ser interpretada de forma mais cuidadosa. Afinal, repensar a igualdade não implica fechar os olhos para a diferença. Num país tão profundamente desigual como o Brasil, no qual a mesma Constituição que exige que a ordem jurídica a que se submetem suas leis seja regida pelo princípio da isonomia, elege entre seus objetivos construir um país de menor desigualdade fática, isso seria temerário. Assim, insistir na importância da efetivação do tratamento igualitário como consecução da virtude soberana da justiça, não é dizer, por exemplo, que diferenciar a alíquota de impostos de acordo com características econômicas da pessoa responsável por realizar seu pagamento, ou instituir políticas de ação afirmativa a favor de determinada parcela social historicamente discriminada, seja ferir de morte o tratamento igualitário.

Dependendo do que se considerar igualdade, certos tratamentos legais podem não ser tão facilmente classificáveis entre igualitários ou discriminatórios. E, mais uma vez, nesses casos, caberá ao Poder Judiciário grande parcela de responsabilidade na definição do que esse tratamento 
igualitário significaria. Mesmo assim, quando a diferenciação legal segue a mesma linha de diferenciação da diferenciação social, instituindo privilégios para aqueles que já são privilegiados na estrutura social, fica difícil dizer em que medida a igual consideração por todos foi preservada. Seria bom que, pelo menos em tais aspectos menos polêmicos, a verdade sobre a igualdade fosse estabelecida diferentemente do que tem sido algumas vezes pelo Poder Judiciário brasileiro e algumas de suas instituições de apoio, como a polícia. Em ambos os casos, no entanto, o debate ainda se encontra em aberto, demandando escolhas políticas e morais dos envolvidos, responsáveis por escrever os novos capítulos do romance em cadeia do Direito brasileiro sob a égide, ou não, da igual consideração e respeito.

Nesse contexto, a cultura e sensibilidade jurídicas locais certamente desempenharão um papel importante, Porém, voltando às lições de Antoine Garapon e Ioannis Papadopoulos (2008, p. 10), tem-se que "[...] a cultura não dita solução alguma - ela [apenas] estabelece a tela de fundo conceitual sobre a qual os debates passam a ter sentido". O debate sobre os rumos da igualdade no direito brasileiro, portanto, está aberto e a tela de fundo sobre a qual ele se desenrola, se é "[...] um retrato autêntico de um objeto obscuro, não pode ser claro, certamente terá de ser obscuro" (WITTGENSTEIN apud GEERTZ, 2008, p. 325). Nesse contexto, esse debate não está fechado nem no seu início nem no seu final. E ele não está inteiramente nas mãos nem dos legisladores, nem dos juristas, nem dos operadores do direito, por mais que a responsabilidade desses últimos tenda a ser a maior. $\mathrm{Na}$ verdade, qualquer transformação do nosso direito terá de reunir a vontade política dessas três frentes sendo que, mais importante que a alteração legislativa e a interpretação teórica, será a sua efetivação nas mãos dos advogados, defensores, promotores e, especialmente, magistrados. Afinal, reconheço a posição privilegiada que um texto acadêmico sobre o assunto possui enquanto instância de produção da verdade - caso contrário, ele não estaria sendo escrito - mas, nesse caso específico, ele não se compara à palavra autorizada do juiz sobre o que é o tratamento igual e, consequentemente, justo, que se espera aqui e agora. 


\section{Referências}

BARROSO, Luís Roberto. Curso de direito constitucional contemporâneo: os conceitos fundamentais e a construção do novo modelo. São Paulo: Saraiva, 2009.

CAPPELLETTI, Mauro. Juizes legisladores? Porto Alegre: Sergio Antonio Fabris Editor, 1993.

CARVALHO, J. M de. Interesses contra a cidadania. In: DA MATTA, R. et al. Brasileiro: cidadão? São Paulo: Cultura Editora Associados, 1992.

DAMATTA, Roberto. O que faz o Brasil, Brasil? Rio de Janeiro: Rocco. 1984.

DWORKIN, Ronald. O Império do direito. São Paulo: Martins Fontes, 2003.

. A virtude soberana: a teoria e a prática da igualdade. São Paulo: Martins Fontes, 2005.

FONSECA, Regina Lúcia Teixeira Mendes de. Igualdade à brasileira: cidadania como instituto jurídico no Brasil. In: AMORIN, Maria Stella; LIMA, Roberto Kant de; TEIXEIRA MENDES, Regina. (Org.). Ensaios sobre a Igualdade Jurídica: acesso à justiça criminal e aos direitos de cidadania no Brasil. Rio de Janeiro: Lúmen Júris, 2005, p.1-34.

. Dilemas da decisão judicial: as representações de juízes brasileiros sobre o princípio do livre convencimento motivado. 2008. 267 f. Tese (Doutorado) - Programa de Pós-Graduação em Direito, Universidade Gama Filho, Rio de Janeiro, 2008.

GARAPON, Antoine. Juiz e a democracia: o guardião das promessas. 2. ed. Rio de Janeiro: Revan, 2001.

GARAPON, Antoine; PAPADOPOULOS, Ioannis. Julgar nos Estados Unidos e na França: cultura jurídica francesa e Common Law em uma perspectiva comparada. Rio de Janeiro: Lumen Juris, 2008. 
GEERTZ, Clifford. O saber local: fatos e leis em uma perspectiva comparada. In: GEERTZ, Clifford. O saber local. Petrópolis: Vozes, 2002, p. 249-356.

MOUZINHO, Gláucia Maria Pontes. Sobre culpados e inocentes: o processo de criminação e incriminação pelo Ministério Público Federal Brasileiro. 2007. 182 f. Tese (Doutorado em Antropologia) - programa de Pós-Graduação em Antropologia, Universidade Federal Fluminense, Niterói RJ, 2007.

NONET, Philippe. SELZNICK, Philip. Direito e sociedade: a transição ao sistema jurídico responsivo. Rio de Janeiro: Revan, 2010.

OLIVEIRA, Luiz Roberto Cardoso de. Direito legal e insulto moral: dilemas da cidadania no Brasil, Quebec e EUA. Rio de Janeiro: Relumé Dumará, 2002.

RAWLS, John. Uma teoria da justiça. 2. ed. São Paulo: Martins Fontes, 2002.

SEN, Amartya. Desigualdade reexaminada. Rio de Janeiro: Record, 2001.

VIANNA, Luiz Werneck et al. Corpo e alma da magistratura brasileira. 3. ed. Rio de Janeiro: Revan, 1997.

VIANNA, Luiz Werneck et al. A judicialização da política e das relações sociais no Brasil. Rio de Janeiro: Revan, 1999. 272 p. 
Igor Suzano Machado é Graduado em Ciências Sociais pela Universidade Federal do Espírito Santo e em Direito pela Faculdade de Direito de Vitória. Mestre em Sociologia pelo Instituto Universitário de Pesquisas do Rio de Janeiro, Universidade Cândido Mendes. Doutor em Sociologia pelo Instituto de Estudos Sociais e Políticos da Universidade Cândido Mendes. Pesquisador do Centro de Estudos Direito e Sociedade. E-mail: igorsuzano@gmail.com.

Endereço profissional: Universidade Federal de Viçosa, Departamento de Ciências Sociais. Av. Henry Rolfs, s/n, Campus Universitário. Viçosa, MG. CEP: 36570-900.

Ludmila Mendonça Lopes Ribeiro possui graduação em Administração Pública pela Fundação João Pinheiro (2001). Graduação em Direito pela Universidade Federal de Minas Gerais (2002). Mestrado em Administração Pública pela Fundação João Pinheiro (2003) e doutorado em Sociologia pelo Instituto Universitário de Pesquisas do Rio de Janeiro (2009). Atualmente é professora do Departamento de Sociologia e Antropologia (DSOA) e pesquisadora do Centro de Estudos de Criminalidade e Segurança Pública (CRISP), ambos da Universidade Federal de Minas Gerais (UFMG). E-mail: ludmila.ribeiro@gmail.com.

Endereço profissional: Universidade Federal de Minas Gerais, Departamento de Sociologia. Av. Presidente Antônio Carlos, n. 6627 - Unidade Adminsitrativa III, Belo Horizonte, MG. CEP: 31270-901. 